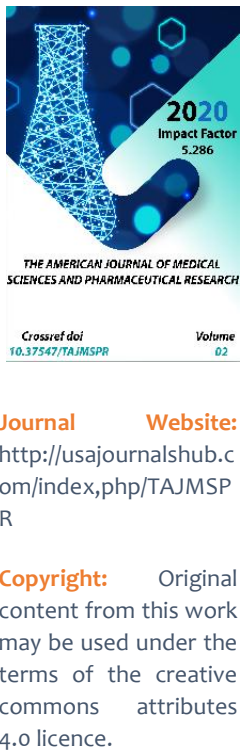

ABSTRACT

\section{«Low-Invasive» A Way Of Surgical Treatment Ulcer Pyloric- Duodenal Stenosis}

\author{
Djamalov S.I. \\ Tashkent Medical Academy, Tashkent, Uzbekistan
}

Aripova N.U.

Tashkent Medical Academy, Tashkent, Uzbekistan

Israilov B.N.

Tashkent Medical Academy, Tashkent, Uzbekistan

Pulatov M.M.

Tashkent Medical Academy, Tashkent, Uzbekistan

Matmuradov S.K.

Tashkent Medical Academy, Tashkent, Uzbekistan

The pyloric-duodenal stenosis (PDS) concerns frequent complications of stomach ulcer and takes the third place after such life-threatening complications duodenal ulcers as punching and ulcer gastrointestinal bleedings. Frequency of occurrence ulcer PDS makes, according to different researchers, $10-18 \%$ and are diagnosed mainly for patients with is long proceeding duodenal an ulcer. Quite often there is simultaneous combination PDS to other complications of stomach ulcer of a duodenal gut that by all means complicates treatment tactics.

\title{
KEYWORDS
}

Anaesthesiologic, duodenoplastic, vagotomy, pyloroplastic, gastro-gastroanastomosis.

\section{INTRODUCTION}

According to a number of the authors, most often meeting complications of stomach ulcer of a duodenal gut had appeared subcompensated and decompensated PDS (17,4\% and 9,6\% accordingly), and also a stenosis in a combination to a penetration $(14,8 \%)$, - with a bleeding $(8,7 \%)$, - with punching $(6,9 \%)[3,4,5]$. The problem of surgical treatment ulcer sub- and decompensated PDS is developed enough. So, in planned that surgery performance of a resection of a stomach or variants vagotomy with antrum - (gemigastr-) ectomy on one of ways of Bilrot or their updatings is expedient. In emergency situations (a combination of a stenosis to a bleeding or punching) the preference is given keep body to interventions $[1,2,5]$. However, in certain cases there are difficulties (both in planned, and in emergency surgery), interfering performance of radical 
operations because of the high operationalanaesthesiologic risk. That concern: advanced age and an exinanition of the patient, perforation an ulcer, combination pyloricduodenal stenosis with gastrectasia and a widespread peritonitis, etc.). In most cases it is required to carry out "minimum", «lowinvasive», during too time proved, operation whenever possible for a short time interval. Usually it is thus carried out vagotomy with various variants pyloric- or duodenoplastic, and application resection methods at times is impossible because of high risk. Some authors recommend carrying out in case of emergency laparoscopic vagotomy and pyloroplastic from miniaccess in the absence of expressed gastrectasia, and in the presence of last antrumectomy [3, 4]. The problem consists that is frequent in the conditions of the high operational-anaestesiologic risk the increased stomach remains untouched, as causes motorevacuation infringements during the postoperative period.

The work purpose: reduction traumatic and duration of operation concerning ulcer PDS with gastrectasia, and the prevention postoperative motor-evacuation frustration for the account increased a stomach.

\section{MATERIALS AND METHODS}

In our clinic (surgical branch of Republican clinical hospital No 1 - base of chair of faculty and hospital surgery of the Tashkent medical academy) is developed «The way of treatment pyloric-duodenal ulcer stenosis» (the Patent NolAP 03921 UZ, 2007) which in our opinion is optimum at patients with ulcer PDS in a combination with gastrectasia in the presence of high operational-anaestesiologic risk (a combination of a stenosis to a bleeding or punching and a widespread peritonitis, advanced age and an exinanition of the patient and etc). The scheme of the offered way it is presented on pictures 1-3, where on pic. 1: 1-trunks n.vagus, a 2-course of " $U$ "shaped goffering seams, a 3-cut for performance pyloroplastic; pic. 2: the scheme of imposing of the modified "single-row" seam on back (4) and a lobby (5) lips at pyloroplastic on Finney; pic. 3: a kind of the finished operation.

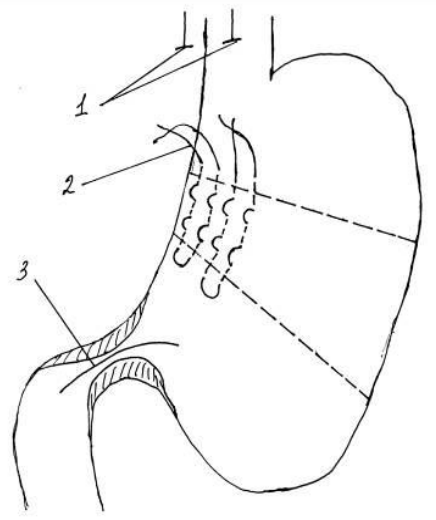

Pic. 1.

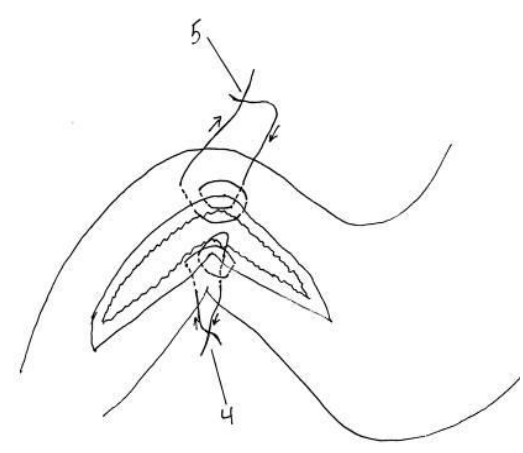

Pic. 2.

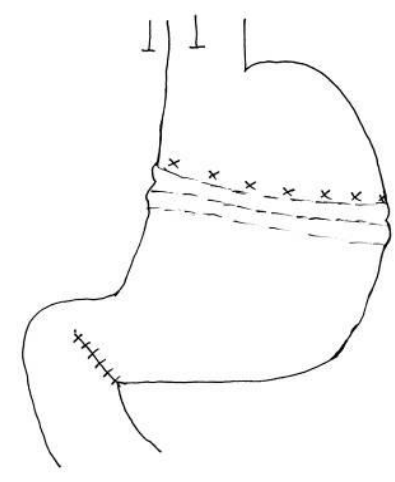

Pic. 3. 
After performance bilaterial trunks vagotomy (1) make mobilisation of an average third of stomach on big and small curvature depending on degree ectasia a stomach (with such calculation that if made a resection of the mobilised segment with the subsequent gastro-gastroanastomosis the stomach would get the normal sizes) and start imposing of " $U$ "-shaped serous-muscular goffering seams (2), in a longitudinal direction in relation to a stomach axis, on a forward and back wall of a stomach (pic. 1). Then make pyloroduodenotomy with capture stenosis a site (3) and start to pyloroplastic (pic. 2). Single-row seam form by two-multiple carrying out of threads through serousmuscular layers along the edges of walls then fasten knot. It is desirable to use atraumatic needles with threads 2/0-3/0. In the same way impose other seams on a back lip. Thus knots are fastened towards a belly cavity, instead of towards an intestinal cavity (i.e. "short moustaches» knots in a body cavity do not stick out). Similar seams form a forward lip anastomosis. On pic. 3 the finished kind of operation is presented. Thus, the normal sizes of a stomach without a segment resection will be restored.

\section{RESULTS AND DISCUSSION}

It is necessary to notice that earlier some authors had been developed ways of reduction of volume ectasia owing to ulcer pyloric-duodenal stenosis of a stomach, which it is considered by the closest to the way developed in our clinic. So, there is "A way of treatment ulcer pyloric-duodenal stenosis" (F.Nazirov et al., 1989, N01678334), based on a resection of a circular segment of a body of a stomach at level of an input of the left gastric artery in small curvature of a stomach before restoration of the normal sizes of a stomach. Then impose gastro-gastroanastomosis and carry out one of known variants drainage an operation stomach - pyloroplastic on Finney or gastroduodenostomy on Djabuley. Rather big expense of time for its performance concerns lacks of the given way and big traumatic at the expense of an extensive resection and formation gastroanastomosis. "The way of treatment of stomach ulcer of the duodenal gut complicated by a stenosis» is known also (Kurka V.I., 1996, RU 206205), including mobilization small curvature with the subsequent gastrofundoplication at which impose serous-muscular seams, keceding from deserous sites of small curvature towards big at an angle, reducing thus a stomach and forming the triangular fold turned to a gullet. Operation also includes selective proximal vagotomy and duodenoplastic after the Hall. However, performance of the given operation demands concerning a long time interval, at performance selective proximal vagotomy small curvature of a stomach is exposed big traumatic, and also at performance gastrofundoplication there is a danger of damage of a spleen because of the tension of seams.

In our opinion, these defects do the abovenamed ways unsuitable in situations when it is required to execute "minimum", «lowinvazive» and well-founded operation, for as it is possible a short time interval (in advanced age and for an exinanition of the patient, perforation to an ulcer, combined with a stenosis and a widespread peritonitis) and there is more apply, basically, in planned surgery of a stomach.

By the offered way it is operated 28 sick ( 15 patients in emergency, 13 - in a planned order) with stomach ulcer of the duodenal gut complicated by pyloric-duodenal stenosis and gastrectasia, specific complications (motornoevakuatornye frustration, an inconsistency of seams and so forth), during the early and late periods after operation, did not observe. 
In a Pic. 4 the image a X-ray review the patient operated by a technique offered by us are presented. It is made control an X-ray review with barium for 5-days, through 1 and 3 month after operation where deformation of

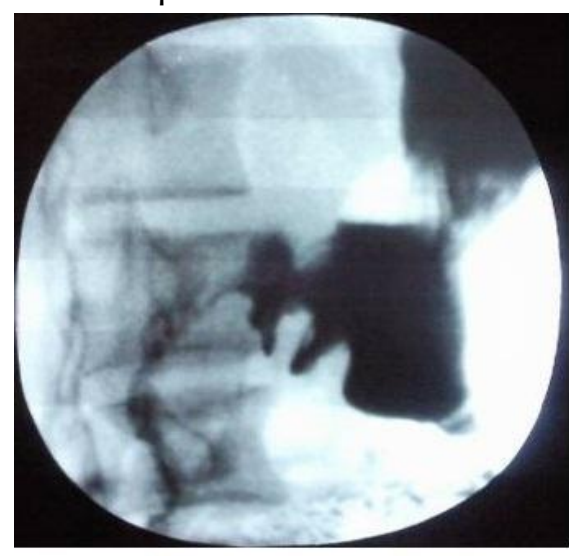

A

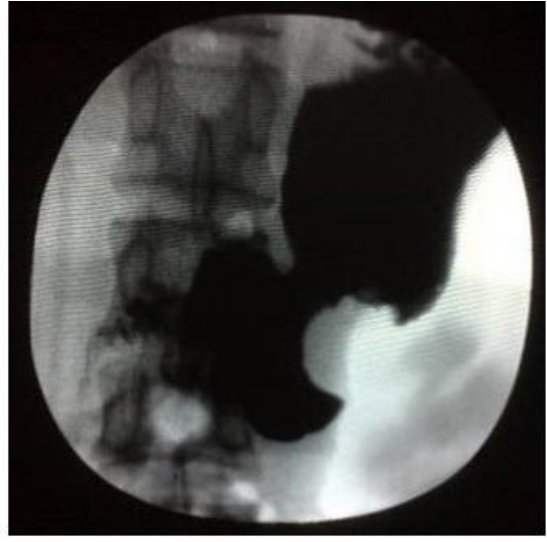

B

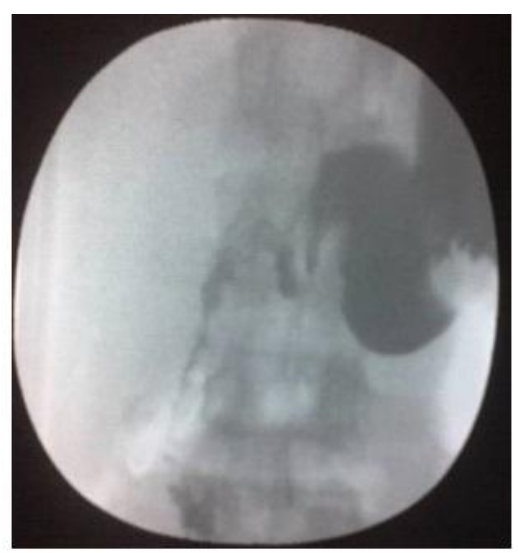

C

Pic. 4.

\section{CONCLUSIONS}

1. The offered way is effective on surgical treatment pyloric-duodenal ulcer stenosis, especially at the elderly and exhausted patients (and in emergency situations) where matters, as pathophysiological an operation substantiation, and its technical simplicity, and shipping patients.

2. The way is simple in workmanship, which does not demand special preparation of the surgeon, special material for a seam and equipment, wide application in gastric surgery therefore can find.

\section{REFERENCES}

1. Bolotov K.S. Laparoskopicheskaya vagotomiya $v$ lechenii patsientov $s$ retsidiviruyuschim techeniem yazvennoy bolezni dvenadtsatiperstnoy kishki: avtoref. dis. ... kand. med. nauk. [Laparoscopic vagotomy in the treatment of patients with recurrent course of duodenal ulcer]. Kemerovo, 2015. contours of a stomach as "sand-glass", the sizes of a stomach normal, contrast evacuation timely is marked $(A, B, C)$.

2. Kapustin B.B. Hirurgicheskoe lechenie yazvennoy bolezni i postgastrorezektsionnyih oslojneniy: avtoref. dis. ... kand. med. nauk. [Surgical treatment of peptic ulcer and post-gastro-resection complications].Ufa, 2010.

3. Cherepanin A.I., Antonov O.N., Ryibelchenko A.V., Sherov R.R. Treatment of patients with bleeding ulcers associated with pyloroduodenal stenosis. V sb.: Mater. III syezda hirurgov Yuga Rossii. [Materials of the III Congress of Surgeons of the South of Russia]. Astrakhan, 2013, p. 97-98. (In Russian).

4. Pajitnov S.M., Esyutin I.N. Hirurgicheskaya taktika pri odnovremennom sochetanii yazvennogo stenoza dvenadtsatiperstnoy kishki i krovotecheniya. V sb.: Pirogovskaya hirurgicheskaya nedelya. [Surgical tactics with a simultaneous 
combination of duodenal ulcerative stenosis and bleeding]. S-Peterburg, 2010, p. 193. (In Russian).

5. Grishaeva A.S., Polejaev A.A., Makarov V.I. et al. Surgical treatment of combined complications of gastric and duodenal ulcers. V sb.: XI syezd hirurgov Rossiyskoy Federatsii. [In the collection: XI Congress of Surgeons of the Russian Federation]. Volgograd, 2011, p. 660-661.

\section{Abstract}

A "Method for the treatment of pyloroduodenal ulcerative stenosis" has been developed (Patent No. IAP 03921 RUz, 2007). We operated on 28 patients (15 patients in an emergency, 13 as planned) with duodenal ulcer complicated by pyloroduodenal stenosis and gastrectasia, specific complications (motor-evacuation disorders, inconsistency of sutures, etc.), in the early and late periods after surgery, did not observe.

Key words: pyloroduodenal stenosis, gastrectasia, minimally invasive surgery, "single-row" suture. 